\title{
Effect of Oxygen Concentration and Growth Rate on Glucose Metabolism, Poly- $\beta$-hydroxybutyrate Biosynthesis and Respiration of Azotobacter beijerinckii
}

\author{
By IAN S. CARTER AND EDWIN A. DAWES \\ Department of Biochemistry, University of Hull, Hull HU6 $7 R X$
}

(Received 7 August 1978)

The effect of dissolved oxygen concentration on glucose metabolism, poly- $\beta$-hydroxybutyrate (PHB) synthesis and respiration of nitrogen-fixing Azotobacter beijerinckii was investigated over a range of values spanning oxygen limitation and sufficiency (nitrogen limitation) in continuous culture. The activities of the Entner-Doudoroff enzymes decreased with increasing oxygen supply while glucose-6-phosphate dehydrogenase was unaffected; $\beta$ ketothiolase and acetoacetyl-CoA reductase decreased more markedly, reflecting the fall in PHB content. The metabolic quotients for $\mathrm{O}_{2}$ and $\mathrm{CO}_{2}$ increased rapidly with increasing oxygen supply, in keeping with the respiratory protection of nitrogenase. The specific activities of all these enzymes, and also of fructose-1,6-bisphosphate aldolase, increased with increasing dilution rate under either oxygen or nitrogen limitation, except that both $\beta$-ketothiolase and acetoacetyl-CoA reductase activities fell at the highest dilution rate $\left(0 \cdot 23 \mathrm{~h}^{-1}\right)$ under oxygen limitation. It was concluded that the role of the Entner-Doudoroff sequence as the major route of glucose metabolism in $A$. beijerinckii was unaffected by oxygen concentration and growth rate.

\section{INTRODUCTION}

The importance of oxygen limitation for the accumulation of poly- $\beta$-hydroxybutyrate (PHB) in the strict aerobe Azotobacter beijerinckii was established by Senior et al. (1972) and the effect of dissolved oxygen concentration on certain enzymes of the tricarboxylic acid cycle was reported by Jackson \& Dawes (1976). At low oxygen concentrations differences exist in the patterns of PHB accumulation between nitrogen-fixing and ammoniumgrown $A$. beijerinckii (Ward et al., 1977), while considerable changes in the fructose-1,6bisphosphate aldolase activity of Azotobacter vinelandii in response to dissolved oxygen concentration have been recorded by Nagai et al. $(1971,1974)$.

Previous work focused attention on $\beta$-ketothiolase and acetoacetyl-CoA reductase as key enzymes for PHB synthesis (Senior \& Dawes, 1973) and the Entner-Doudoroff pathway as the major route of glucose catabolism in A. beijerinckii (Senior \& Dawes, 1971; Stephenson et al., 1978), while the effects of transition from oxygen to nitrogen limitation and vice versa on these two enzymes of PHB synthesis were investigated by Jackson \& Dawes (1976). As high oxygen concentrations invoke the mechanism of respiratory protection of the nitrogenase system of nitrogen-fixing Azotobacters (Parker, 1954; Phillips \& Johnson, 1961 ; Dalton \& Postgate, 1968; Drozd \& Postgate, 1970), characterized by very high respiratory rates at the expense of the available carbon source, it was important to discover whether a switch to oxygen limitation affected either the pattern of glucose metabolism or the levels of the enzymes concerned or both. The present work was undertaken to study 
the effects of oxygen limitation and sufficiency over a range of oxygen supply rates, and also dilution rates, on PHB biosynthesis, glucose catabolism and respiration of both steady-state and transitional-state chemostat cultures of nitrogen-fixing $A$. beijerinckii.

\section{METHODS}

Organism. The organism was a capsuleless variant of Azotobacter beijerinckii NCIB 9067, first isolated by Senior et al. (1972), and now lodged as NCIB 11292.

Growth conditions. Details of the chemostat used, the media for batch and continuous culture, the maintenance of cultures, growth conditions, bacterial dry weight measurements and determination and control of dissolved oxygen tension in the culture were given by Senior et al. (1972). Organisms were grown at $30^{\circ} \mathrm{C}$ and, except for experiments on the effect of growth rate, at a dilution rate of $0.1 \mathrm{~h}^{-1}$. For the oxygenlimited cultures, the nitrogen flow rate was $800 \mathrm{ml} \mathrm{min}^{-1}$ and the oxygen flow rate was adjusted as stated in Results; for the nitrogen-limited cultures, the nitrogen flow rate was $20 \mathrm{ml} \mathrm{min}^{-1}$, the oxygen/nitrogen mixture was diluted with $591 \mathrm{ml}$ argon min $^{-1}$ and the oxygen flow rate was adjusted as stated in Results.

Analyses. The determination of glucose in the culture media and metabolic quotients in situ were as given by Senior $e t$ al. (1972). The method of McInnes et al. (1958) was used to prepare fully methylated samples of lyophilized supernatants from the culture media, and these were examined for metabolic products using a Pye Unicam Series 104 chromatograph with a flame-ionization detector.

Poly- $\beta$-hydroxybutyrate was determined by a modification of the spectrophotometric method of Law \& Slepecky (1961). A culture sample $(20 \mathrm{ml})$ was centrifuged and resuspended in an equal volume of distilled water $\left(4{ }^{\circ} \mathrm{C}\right) ; 2 \mathrm{ml}$ portions of this suspension were used for dry weight determinations and $5 \mathrm{ml}$ portions were lyophilized in $250 \mathrm{ml}$ round-bottomed flasks. The lyophilized cultures were refluxed for $2 \mathrm{~h}$ with $70 \mathrm{ml}$ chloroform and filtered. The filtrates were subjected to rotary evaporation to leave a thin film of PHB which was washed consecutively with water, ethanol, acetone and ether. The washed samples were redissolved in chloroform and measured spectrophotometrically at $235 \mathrm{~nm}$ after heating with conc. sulphuric acid, as in the assay of Law \& Slepecky (1961). The standard error of the estimations was less than $5 \%$.

Enzyme assays. Bacterial extracts were prepared by the methods of Senior \& Dawes (1973). All enzyme assays were done at $30{ }^{\circ} \mathrm{C}$ with a Pye Unicam SP1800 recording spectrophotometer under previously determined optimum conditions. $\beta$-Ketothiolase (EC 2.3.1.9) and acetoacetyl-CoA reductase (EC 1.1.1.36) were assayed as described by Senior \& Dawes (1973); glucose-6-phosphate dehydrogenase (EC 1.1.1.49), fructose-1,6-bisphosphate aldolase (EC 4.1.2.13) and the combined activities of 6-phosphogluconate dehydratase (EC 4.2.1.12) and 3-deoxy-2-oxo-6-phosphogluconate aldolase (EC 4.1.2.14) were assayed by the methods of Stephenson et al. (1978).

Chemicals and biochemicals. Analytical reagent grade chemicals from Hopkin \& Williams and B.D.H. were used wherever possible. Biochemicals were obtained from Sigma and Boehringer.

\section{RESULTS AND DISCUSSION}

\section{Steady-state measurements of the effects of oxygen concentration at a fixed dilution rate}

The variations with oxygen supply of PHB content and of activities of enzymes of PHB and glucose metabolism in steady-state cultures of $A$. beijerinckii grown at a dilution rate of $0 \cdot 1 \mathrm{~h}^{-1}$ are shown in Fig. 1. At low rates of oxygen supply, the culture was oxygenlimited [undetectable dissolved oxygen tension (d.o.t.)] and the bacterial dry weight was a function of the oxygen content of the inflowing gas. At high d.o.t. values, the culture became nitrogen-limited with bacterial density determined by the nitrogen concentration: in these experiments the total gas flow rate was held constant by diluting the oxygen/ nitrogen mixture with argon. Under these conditions the d.o.t. increased with increase in oxygen supply.

The activities of $\beta$-ketothiolase and acetoacetyl-CoA reductase, enzymes essential for PHB biosynthesis, fell and were mirrored by the decrease in intracellular PHB as the oxygen input was increased (Fig. 1). These results emphasize the importance of the environmental oxygen concentration for PHB biosynthesis under conditions of either oxygen or nitrogen limitation. Thus nitrogen-limited cultures with a low environmental oxygen con- 


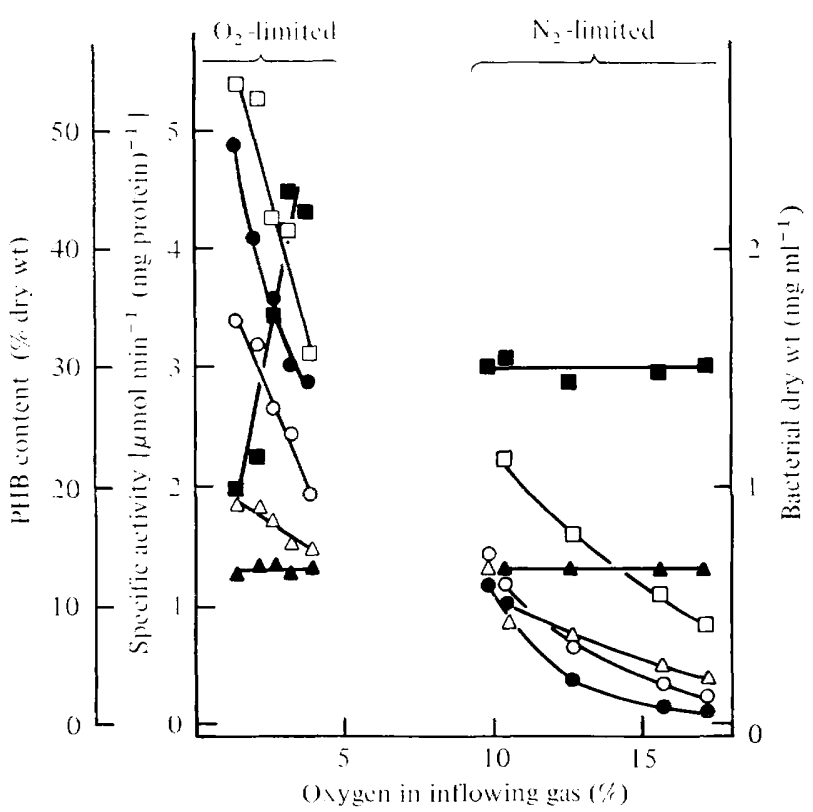

Fig. 1. Effect of oxygen supply in a chemostat culture of nitrogen-fixing A. beijerinckii on activities of $\beta$-ketothiolase $(\square)$, acetoacetyl-CoA reductase $(\bigcirc)$, glucose-6-phosphate dehydrogenase $(\boldsymbol{\Delta})$ and Entner-Doudoroff enzymes $(\Delta)$, poly- $\beta$-hydroxybutyrate content $(\boldsymbol{O})$ and bacterial dry weight $(\boldsymbol{\sigma})$. The dilution rate was $0 \cdot 1 \mathrm{~h}^{-1}$. The d.o.t. was undetectable under the oxygen-limited conditions.

centration $(10 \%$ in inflowing gas; d.o.t. $0 \cdot 2 \mathrm{kPa})$ contained about $12 \% \mathrm{PHB}$ and this polymer content decreased to a negligible value as the oxygen concentration was increased to $17 \%$ of the inflowing gas (d.o.t. $2.0 \mathrm{kPa}$ ). The activity of the combined Entner-Doudoroff enzymes decreased as the oxygen concentration was increased while glucose-6-phosphate dehydrogenase activity was independent of the oxygen concentration (Fig. 1). These results contrast with those reported for $A$. vinelandii by Haaker \& Veeger (1976) who found higher glucose-6-phosphate dehydrogenase activity under nitrogen limitation than under oxygen limitation while Entner-Doudoroff activity was similar under both limitations, at a dilution rate of $0.1 \mathrm{~h}^{-1}$. However, these workers reported only one value for each limitation. Although Entner-Doudoroff activity decreased with increasing d.o.t. and respiratory rate, even at the highest recorded $Q_{\mathrm{O}_{2}}$ the enzyme capacity was well in excess of that required to sustain the observed respiration rate - the respective rates corresponded to 0.40 and $0 \cdot 24 \mu \mathrm{mol}$ glucose utilized $\mathrm{min}^{-1}$ (mg protein) ${ }^{-1}$.

The metabolic quotients of $A$. beijerinckii increased with increasing oxygen supply (Fig. 2). At the lowest oxygen supply rates, the bacterial densities were very low and the gas measurements were therefore subject to error; consequently the apparently marked fall in respiratory quotient with decreasing oxygen concentration in this region must be treated with caution. The increased efficiency of glucose utilization to produce biomass, principally as PHB, may be noted at the low oxygen supply rates (Fig. 2). The rapid increase of respiration rate with increasing oxygen concentration is a manifestation of the respiratory protection of nitrogenase.

\section{Transitional-state studies of the effects of oxygen concentration}

These experiments on glucose catabolic enzymes were designed to supplement our previous studies on the response of various enzymes of PHB metabolism and the tricarboxylic 


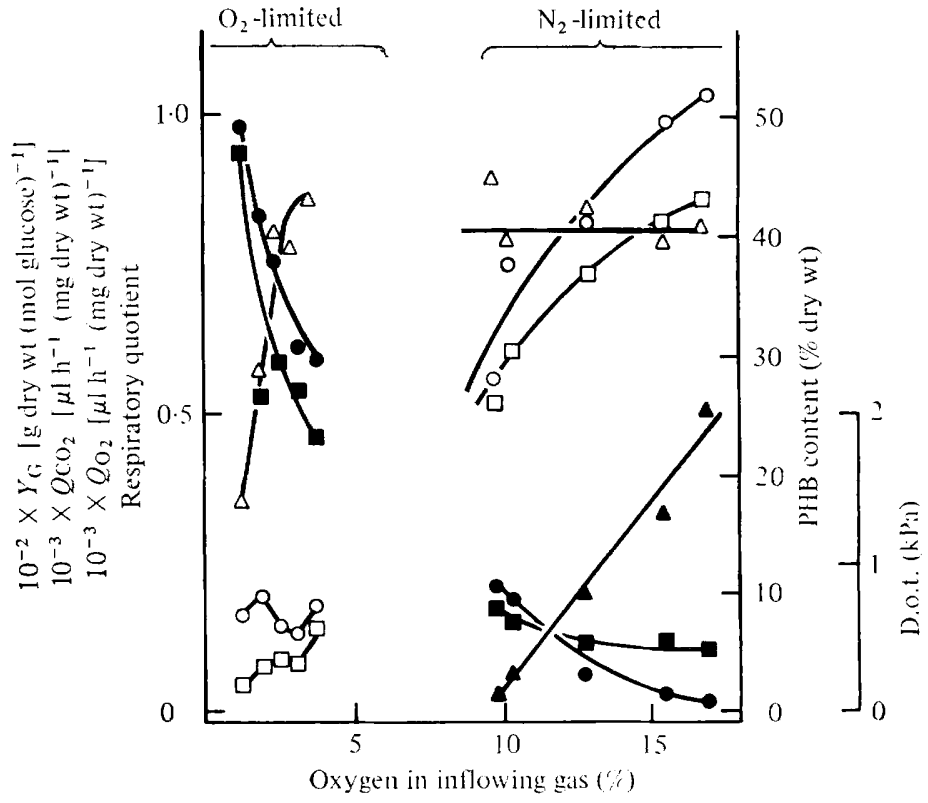

Fig. 2. Effect of oxygen supply in a chemostat culture of nitrogen-fixing $A$. beijerinckii on poly- $\beta$ hydroxybutyrate content $(\boldsymbol{O})$, glucose growth yield $\left(Y_{\mathrm{G}}\right)(\boldsymbol{\sigma})$, metabolic quotients with respect to oxygen $\left(Q_{\mathrm{O}_{2}}\right)(O)$ and carbon dioxide $\left(Q_{\mathrm{CO}_{2}}\right)(\square)$, respiratory quotient $(\triangle)$ and dissolved oxygen tension (d.o.t.) ( $\Delta$ ). The dilution rate was $0 \cdot 1 \mathrm{~h}^{-1}$. The d.o.t. was undetectable under the oxygen-limited conditions.

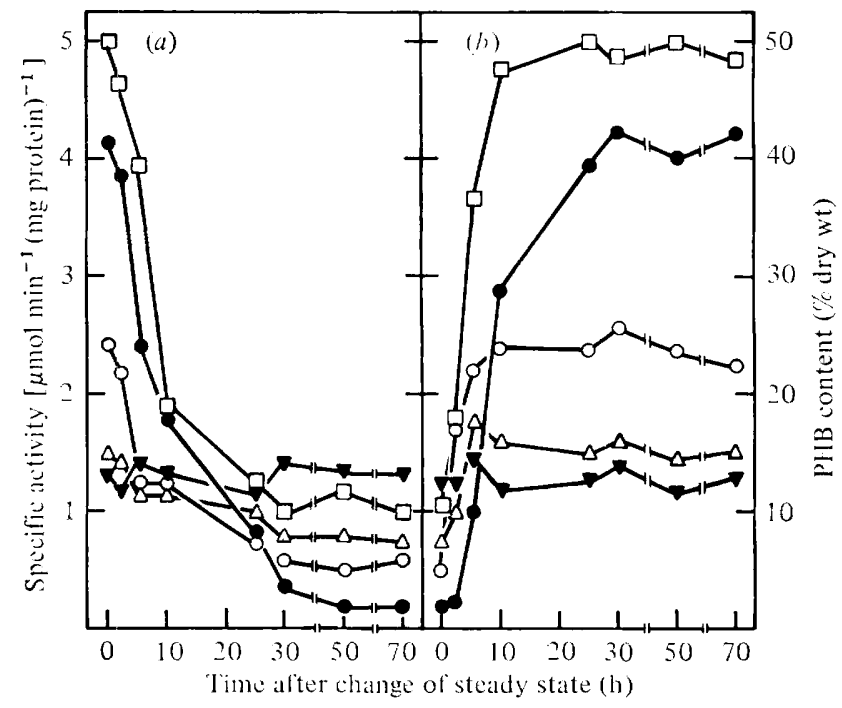

Fig. 3. Effect of transition from oxygen to nitrogen limitation, and vice versa, of a chemostat culture of nitrogen-fixing $A$. beijerinckii on activities of $\beta$-ketothiolase ( $\square$ ), acetoacetyl-CoA reductase $(O)$, glucose-6-phosphate dehydrogenase $(\boldsymbol{\nabla})$ and Entner-Doudoroff enzymes $(\triangle)$, and poly- $\beta$-hydroxybutyrate content $(\Theta)$. The dilution rate was $0 \cdot 1 \mathrm{~h}^{-1}$. At zero time, the cultural conditions were changed from $(a)$ oxygen limitation [undetectable dissolved oxygen tension (d.o.t.)] to nitrogen limitation (d.o.t. $0.8 \mathrm{kPa}$; (b) nitrogen limitation (d.o.t. $0.8 \mathrm{kPa}$ ) to oxygen limitation. 


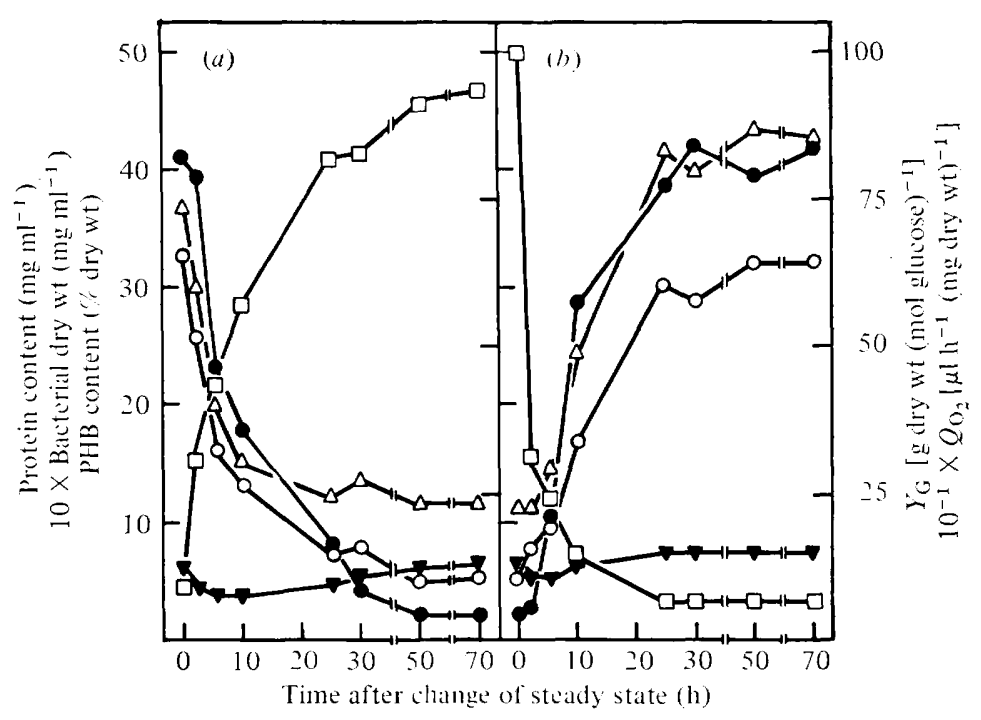

Fig. 4. Effect of transition from oxygen to nitrogen limitation, and vice versa, of a chemostat culture of nitrogen-fixing $A$. beijerinckii on poly- $\beta$-hydroxybutyrate content (O), glucose growth yield $\left(Y_{\mathrm{G}}\right)(\bigcirc)$, metabolic quotient with respect to oxygen $\left(Q_{\mathrm{O}_{2}}\right)(\square)$, protein content $(\nabla)$ and bacterial dry weight $(\triangle)$. Conditions and other details were as for Fig. 3.

acid cycle to oxygen concentration (Jackson \& Dawes, 1976). To facilitate direct comparison with the earlier experiments, measurements of $\beta$-ketothiolase and acetoacetyl-CoA reductase activities and PHB content were included with those of glucose-6-phosphate dehydrogenase and the Entner-Doudoroff enzymes.

The glucose-catabolizing enzymes showed relatively little change; the combined activity of the Entner-Doudoroff enzymes decreased on imposition of a nitrogen limitation and increased again on re-imposition of an oxygen limitation while no significant change in glucose-6-phosphate dehydrogenase activity was observed (Fig. 3), in keeping with the steady-state culture observations. The behaviour of the enzymes of PHB metabolism, and PHB content, confirmed the pattern previously established (Jackson \& Dawes, 1976). The bacterial dry weight reflected the changes in PHB content while the protein concentration of the culture remained almost constant in the two steady states, falling slightly at the beginning of each transition (Fig. 4). The growth yield on glucose fell on imposition of the nitrogen limitation and the $Q_{\mathrm{o}_{2}}$ rose; the changes were reversed on re-imposition of the oxygen limitation (Fig. 4). Culture supernatants were examined for metabolic products but none was detected under either limitation.

\section{Steady-state studies of the effect of dilution rate on enzymes of glucose and PHB metabolism}

Our previous work (Senior et al., 1972) had revealed changes in biomass yield, PHB content and $\mathrm{CO}_{2}$ production with dilution rate and a study of its effect on enzymes of glucose and PHB metabolism for oxygen- and nitrogen-limited cultures was therefore undertaken (Table 1). The activities of all the enzymes measured displayed an increase with increasing dilution rate, although $\beta$-ketothiolase and acetoacetyl-CoA reductase activities fell at the highest dilution rate $\left(0 \cdot 23 \mathrm{~h}^{-1}\right)$ under oxygen limitation. A decrease in PHB content with increase in dilution rate, previously recorded by Senior et al. (1972), was confirmed for such oxygen-limited cultures and, at all dilution rates, the activities of the two key enzymes of PHB metabolism were greatly in excess of those necessary to sustain 


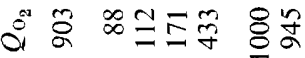

3

ì

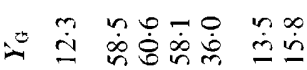

g

$: \approx$

$\lambda^{b}$

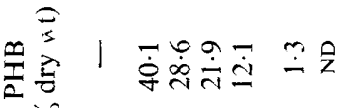

$\therefore$ 产

$\stackrel{5}{\circ}$

㝕

焉

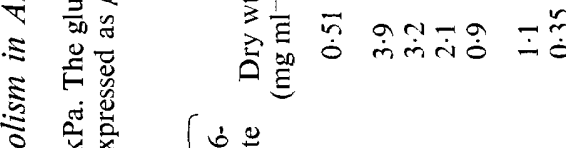

$\stackrel{5}{2}$

$\underset{\infty}{+\infty}$

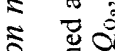

ป

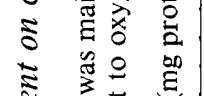

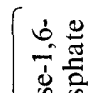

方㠃

出舟需

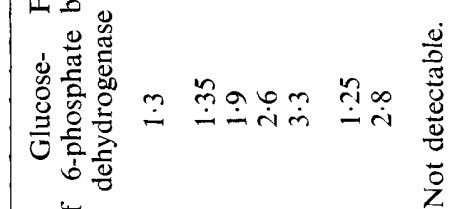

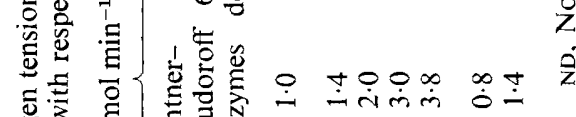

离

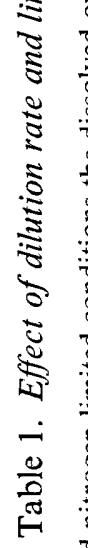

马्ये

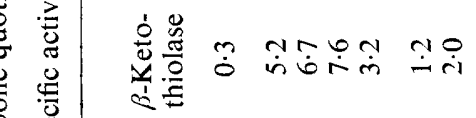

क

宥

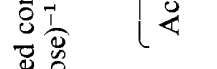

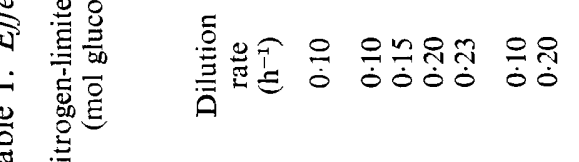

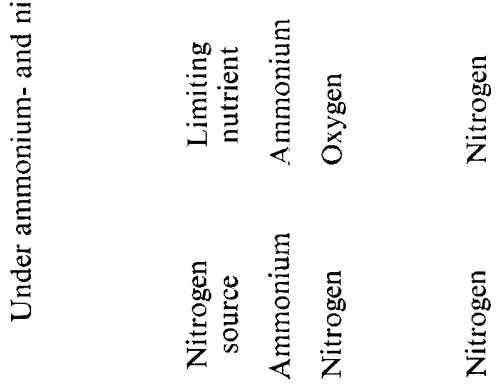


the observed PHB contents. At a constant dilution rate, a correlation existed between the activities of these enzymes and the PHB content, as noted in Figs 1 and 3.

The role of fructose-1,6-bisphosphate aldolase in $A$. beijerinckii, which lacks phosphofructokinase and therefore cannot glycolyse (Stephenson et al., 1978), lies presumably in hexose phosphate formation from triosephosphates; its activity under all conditions was substantially lower than that of glucose-6-phosphate dehydrogenase or the combined Entner-Doudoroff enzymes and could not satisfy the observed rates of overall glucose metabolism. Nagai et al. (1971) claimed that fructose-1,6-bisphosphate aldolase activity of $A$. vinelandii increased linearly with oxygen concentration up to $42 \%$ of air saturation, but subsequently discovered this was an artefact of their technique (which also changed the dilution rate) and that activity attained a plateau value at $13 \%$ of air saturation (Nagai et al., 1974). Without experimental evidence, they invoked the operation of the oxidative pentose cycle to explain their observations (Nagai et al., 1971), despite the reported absence of 6-phosphogluconate dehydrogenase in A. vinelandii (Mortenson et al., 1955). Carbohydrate metabolism in $A$. beijerinckii is controlled at the hexose phosphate level by glucose6-phosphate dehydrogenase, an allosteric enzyme modulated by ATP, ADP, NADH and NADPH (Senior \& Dawes, 1971). It is noteworthy, therefore, that the level of this enzyme is unaffected by nutrient limitation at a constant dilution rate (Fig. 1, Table 1). Further, 6-phosphogluconate dehydrogenase is absent from $A$. beijerinckii (Stephenson et al., 1978) so that an oxidative pentose cycle does not operate. The available evidence thus indicates that oxygen limitation does not affect the route of glucose metabolism in this organism and the Entner-Doudoroff sequence is the major pathway.

We are grateful to the Agricultural Research Council for a grant-in-aid and to Mr I. D. Marriott for expert technical assistance.

\section{REFERENCES}

Dalton, H. \& Postgate, J. R. (1968). Effect of oxygen on growth of Azotobacter chroococcum in batch and continuous cultures. Journal of General Microbiology 54, 463-473.

Drozd, J. \& Postgate, J. R. (1970). Effects of oxygen on acetylene reduction, cytochrome content and respiratory activity of Azotobacter chroococcum. Journal of General Microbiology 63, 63-73.

HAAKER, H. \& VeEger, C. (1976). Regulation of respiration and nitrogen fixation in different types of Azotobacter vinelandii. European Journal of Biochemistry 63, 499-507.

JACKsON, F. A. \& DAwES, E. A. (1976). Regulation of the tricarboxylic acid cycle and poly- $\beta$ hydroxybutyrate metabolism in Azotobacter beijerinckii grown under nitrogen or oxygen limitation. Journal of General Microbiology 97, 303. 312.

LAW, J. H. \& Slepecky, R. A. (1961). Assay of poly- $\beta$-hydroxybutyric acid. Journal of Bacterio$\log y$ 82, 33-36.

MCInnes, A. G., Ball, D. H., CoOper, F. P. \& Bishop, C. T. (1958). Separation of carbohydrate derivatives by gas-liquid partition chromatography. Journal of Chromatography 1, 556-557.

Mortenson, L. E., Hamilton, P. B. \& Wilson, P. W. (1955). Dissimilation of 6-phosphogluconate by Azotobacter vinelandii. Biochimica et biophysica acta 16, 238-244.
Nagai, S., Nishizawa, Y., Onodera, M. \& Aiba, S. (1971). Effect of dissolved oxygen on growth yield and aldolase activity in chemostat culture of Azotobacter vinelandii. Journal of General Microbiology 66, 197-203.

NaGai, S., Nishizawa, Y. \& AJba, S. (1974). Some consideration on the rate of induced aldolase synthesis in Azotobacter vinelandii. Journal of General and Applied Microbiology 20, 229-241.

Parker, C. A. (1954). Effect of oxygen on nitrogen fixation by Azotobacter. Nature, London 173, $780-781$.

Phillips, D. A. \& Johnson, M. J. (1961). Aeration in fermentations. Journal of Biochemical and Microbiological Technology and Engineering 3, 277-309.

Senior, P. J. \& Dawes, E. A. (1971). Poly- $\beta$ hydroxybutyrate biosynthesis and the regulation of glucose metabolism in Azotobacter beijerinckit. Biochemical Journal 125, 55-66.

SENIOR, P. J. \& DAwES, E. A. (1973). The regulation of poly- $\beta$-hydroxybutyrate metabolism in Azotobacter beijerinckii. Biochemical Journal 134, 225-238.

Senior, P. J., Beech, G. A., Ritchie, G. A. F. \& Dawes, E. A. (1972). The role of oxygen limitation in the formation of poly- $\beta$-hydroxybutyrate during batch and continuous culture of Azotobacter beijerinckii. Biochemical Journal 128, 1193-1201. 
Stephenson, M. P., Jackson, F. A. \& Dawes, E. A. Ward, A. C., Rowley, B. I. \& Dawes, E. A. (1977). (1978). Further observations on carbohydrate metabolism and its regulation in Azotobacter beijerinckii. Journal of General Microbiology 109, 89-96. Effect of oxygen and nitrogen limitation on poly$\beta$-hydroxybutyrate biosynthesis in ammoniumgrown Azotobacter beijerinckii. Journal of General Microbiology 102, 61-68. 